\title{
A Comparison of Bilateral Decompression via Unilateral Approach and Classic Laminectomy in Patients with Lumbar Spinal Stenosis in terms of postoperative back pain.
}

\author{
Osama Ahmad Khan, Muhammad Pervez Khan, Muhammad Azam, Zainul Abideen, Shams Uddin
}

\section{ABSTRACT}

Back ground: Lumbar spinal stenosis (LSS) is a common cause of morbidity in elderly patients due to degenerative changes of spine. Different surgical procedures have been proposed including open lumbar laminectomy and other less invasive decompressive procedures to minimize soft tissue damage and lessen the post-operative complication. So we conducted this study to find more appropriate and less invasive procedure.

Objective: To compare mean post-operative back pain score in patients with lumbar spinal stenosis undergoing bilateral decompression via unilateral approach versus classic laminectomy.

Material and Methods: This randomized control trial was carried out in department of neurosurgery, Saidu Teaching Hospital Sharif Swat from April 2018 to October 2018.A total of 60 patients having confirmed degenerative lumbar spine stenosis with pain score of $>5$ on Visual Analogue Score (VAS) presenting in outpatient department were included in the study. Patients not willing for the study and fulfilling the set exclusion criteria were excluded. Patients were divided in two groups randomly on basis of lottery method. Written informed consent was taken and VAS at presentation of all patients was recorded. In group A patient underwent bilateral decompression via unilateral approach. In-group B patient underwent classic laminectomy. Pain evaluation in both groups via Visual Analogue Scoring was recorded before surgery and at 1 month post-operative follow-up. Follow up was advised at a 2 weeks interval and final outcome was measured at 1 month post operatively. Data collected was analyzed through SPSS 22.

Results: In our study the mean age of the patients was $59.12 \pm 12.88$ years, the male to female ratio was $0.9: 1$. Statistically highly significant difference was found between the study groups with pain at $1^{\text {st }}$ month i.e. $p$-value $=0.000$.

Conclusion: The bilateral decompression via unilateral approach had significantly reduced post-operative pain as compared to classic laminectomy in patients with LSS.

Key words: pain, classic laminectomy, bilateral decompression, unilateral approach, lumbar spinal Stenosis

This article may be cited as: Khan OA, Khan MP, Azam M, Abideen Z, Uddin S.A Comparison of Bilateral Decompression via Un ilateral Approach and Classic Laminectomy in Patients with Lumbar Spinal Stenosis in terms of postoperative back pain. J Saidu Med Coll Swat 2021;11(1):45-49

\section{INTRODUCTION}

Lumbar spinal stenosis is a common cause of morbidity in elderly patients due to degenerative changes of spine ${ }^{1}$. These degenerative changes include growth involving facet joints, hypertrophic changes in ligamentum flavum, osteophytes and disc changes causing the narrowing of spinal canal which results in compression symptoms of spinal cord and their nerve roots ${ }^{1-5}$. The incidence of lumbar spinal stenosis is estimated to be around 5 cases per 100,000 individuals with increase in prevalence with increasing age ${ }^{6}$. It is more common in women mostly occurs in seventh decade of life ${ }^{4}$. The symptoms of lumbar spinal stenosis include lower back ache, pain radiating down the leg which increases on walking, numbness and motor weakness ${ }^{1-4}$. These symptoms limits the daily life activities and increases the risk of fall ${ }^{1,2}$. It has been hypothesized that microvascular damage due to prolonged compression of the spinal cord and their nerve roots leading to ischemia, edema and

Department of Neurosurgery SGTH/SMC, Swat

Correspondence: Dr. Osama Ahmad Khan

Mohalla Ibrahim Khail Village Odigram

Tehsel Babozai, Swat

Email:xbundlz@gmail.com demyelination of nerves causes these symptoms ${ }^{7}$. Treatment options include non-surgical and surgical options. Non-surgical includes restriction of activity, posture modification, oral analgesics including NSAIDs and mild opioids, physical therapy and epidural steroid injections for pain management ${ }^{6,8}$. There has been no standard in non-operative treatment of patients with lumbar spinal stenosis and it varies with the treating physician ${ }^{8}$. Patients who do not respond to nonsurgical treatment or those having severe form of stenosis are considered for surgical treatment ${ }^{4,6,9}$.

Different surgical procedures have been proposed for decompression of patients with lumbar spinal stenosis including open lumbar laminectomy, and other less invasive decompressive procedures ${ }^{9}$. Classic or open laminectomy was considered to be gold standard treatment for lumbar spinal stenosis ${ }^{8-10}$. Classic laminectomy includes dissection through paraspinal muscles, lamina and facet joints, spinous process with its related ligaments. This causes greater soft tissue insult which results in post-operative complications including chronic back ache, failed back surgery syndrome and prolonged hospital stay ${ }^{4,6,10,11}$. 
Less invasive surgical procedures have been proposed to minimize soft tissue damage and lessen the post-operative complication and hospital stay ${ }^{6,8,10,11}$. These include unilateral micro decompression and bilateral decompression via unilateral approach which are preferred over conventional open laminectomy ${ }^{1,9}$. An international study conducted by Yaman $\mathrm{O}$ et al. shows that Post-operative lower back pain mean VAS score was significantly lower in patients at 1 month follow up who underwent bilateral decompression via unilateral approach $(2.03 \pm 0.48)^{1}$ as compared to those who underwent classic laminectomy $(4.08 \pm 0.81)^{1}$.

Rationale of this study is to encourage and promote the use of less invasive procedure with fewer post-operative complications instead of classic laminectomy which is still widely done in our setups for management of patients with lumbar spinal stenosis. This comparison of postoperative pain between classic laminectomy and less invasive bilateral decompression via unilateral approach has not been done in our population.

\section{.MATERIALAND METHODS}

This randomized control trial (RCT) was carried out in the department of neurosurgery, Saidu Teaching Hospital Sharif Swat from April 2018 to October 2018.

Patients aged 35-80 years of either gender in whom conservative management have failed and having confirmed lumbar spinal stenosis with a pain score of more than 5 on Visual Analogue Score (VAS 0-10), 0 taken as "No pain"and 10 as "Worst possible pain" as shown below were included in the study.

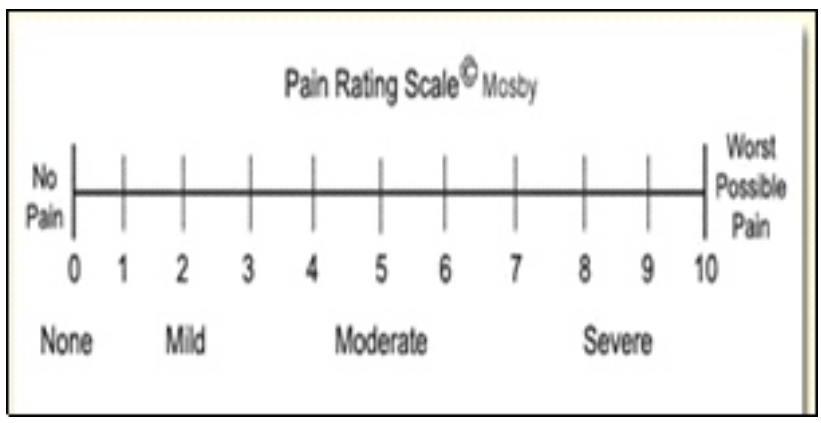

Written informed consent was taken from all the patients meeting the inclusion criteria. Patients having history of previous spine surgery, acute trauma, backache due to pathology other than degenerative lumbar spinal stenosis, unfit for surgery and unwilling to be part of the study were excluded. Patients were divided in two groups randomly on basis of lottery method. VAS at presentation of all patients was recorded. Group A patients underwent bilateral decompression via unilateral approach in which after routine unilateral exposure to the lamina, a partial laminectomy of the cephalad lamina and a portion of the caudal lamina using a high-speed drill was performed. The laminectomy was extended cephalad until the region of insertion of the ligamentum flavum was reached followed by a small laminectomy on the ipsilateral caudal lamina. The soft tissue and bony stenotic portions were excised using Kerrison rongeurs or a chisel at the subarticular zone. The procedure was done sequentially until the nerve root at the operative level was observed to exit freely into the foramen. After ipsilateral decompression, the contralateral side was addressed. Group B patient underwent classic laminectomy in which lamina and ligamentum flavum in the affected area was removed. All the operative procedures were done by consultant neurosurgeon. Pain evaluation in both groups via Visual Analogue Scoring was recorded before surgery and at 1 month Postoperative follow-up. Follow up was advised at 2 weeks interval and final outcome was measured at 1 month post operatively.

Data was collected in the form of variables and was analyzed on SPSS Version 22. Frequencies and percentages were calculated for qualitative data i.e. gender. Mean and standard deviation were calculated for quantitative data i.e. age and VAS. Independent samples t-test was used to compare pain score at 1 month after surgery in both groups. A p-value $\leq 0.05$ was considered statistically significant. Effect modifiers like age, gender was controlled by stratification. Post stratification independent sample t-test was applied.

\section{RESULTS}

In this present study total 60 cases were enrolled. The mean age of the patients was $59.12 \pm 12.88$ years with minimum and maximum ages of $35 \&$ 80 years respectively. In this study the mean age of the group A patients was $58.50 \pm 13.41$ years and its mean age in group $B$ patients was $59.73 \pm 12.54$ years. 
In our study 29 patients were males in which 13 were from group $A$ and 16 were from group $B$, similarly the female patients were 31 in which 17 were from group $A$ and 14 were from group $B$ as shown in the chart below.

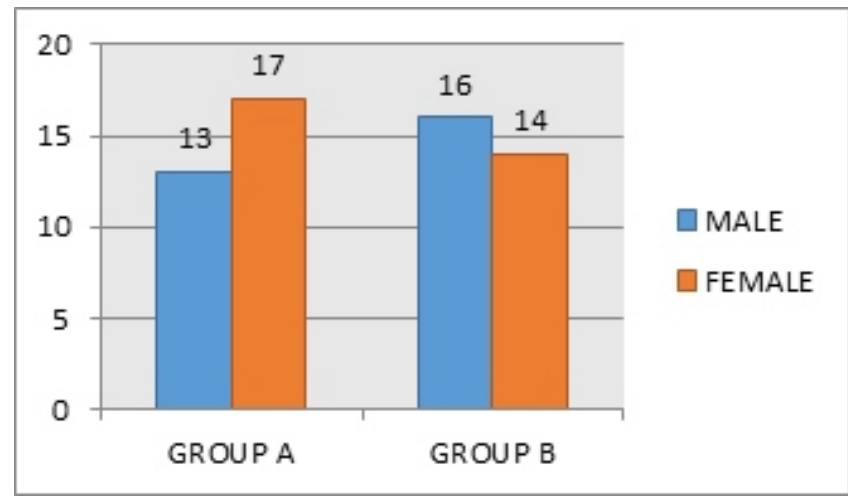

The study results showed that the mean value of pain at presentation in group Awas $8.47 \pm 1.48$ and its mean value in group $B$ was $7.87 \pm 1.41$. Statistically insignificant difference was found between the study groups with pain at presentation i.e. $p$-value $=0.113$ as outlined in Table 1.

In this study the mean value of pain at $1^{\text {st }}$ month in group A was 1.63 \pm 1.129 and its mean value in group B was $3.50 \pm 1.106$. Statistically highly significant difference was found between the study groups with pain at $1^{\text {st }}$ month i.e. pvalue $=0.000$ as shown in the Table 2 below.

The study results showed that in $=55$ years patients, the mean value of pain at $1^{\text {st }}$ month in group A was $1.69 \pm 1.032$ and its mean value in group B was $3.30 \pm 1.25$, similarly in $>55$ years patients the mean value of pain at $1^{\text {st }}$ month in group A was $1.59 \pm 1.23$ and its mean value in group B was $3.60 \pm 1.046$. Statistically significant difference was found between the pain at $1^{\text {st }}$ month with study groups stratified by age i.e. $p$ value $=0.003 \& 0.000$ respectively.

The study results showed that in male patients, the mean value of pain at $1^{\text {st }}$ month in group $A$ was $1.62 \pm 1.26$ and its mean value in group $B$ was $3.88 \pm 1.08$, similarly in female patients the mean value of pain at $1^{\text {st }}$ month in group A was $1.65 \pm 1.05$ and its mean value in group B was 3.07 \pm 0.99 . Statistically significant difference was found between the pain at $1^{\text {st }}$ month with study groups stratified by gender i.e. p-value $=0.000 \& 0.001$ respectively.

\section{DISCUSSION}

This present randomized control trial was carried out at Saidu Teaching Hospital Saidu Sharif Swat, department of neurosurgery to compare mean post-operative back pain score in patients with LSS undergoing bilateral decompression via unilateral approach versus classic laminectomy. Pain radiating to lower extremities is a frequent complaint, especially in elderly people, and LSS is one of the underlying conditions. Several surgical techniques for lumbar spine decompression have been described over last few decades. ${ }^{12}$ Conventional laminectomy is frequently associated with surgical failures, generally related to postoperative iatrogenic spinal instability. ${ }^{13}$

Table 1. Comparison of pain at presentation with study groups

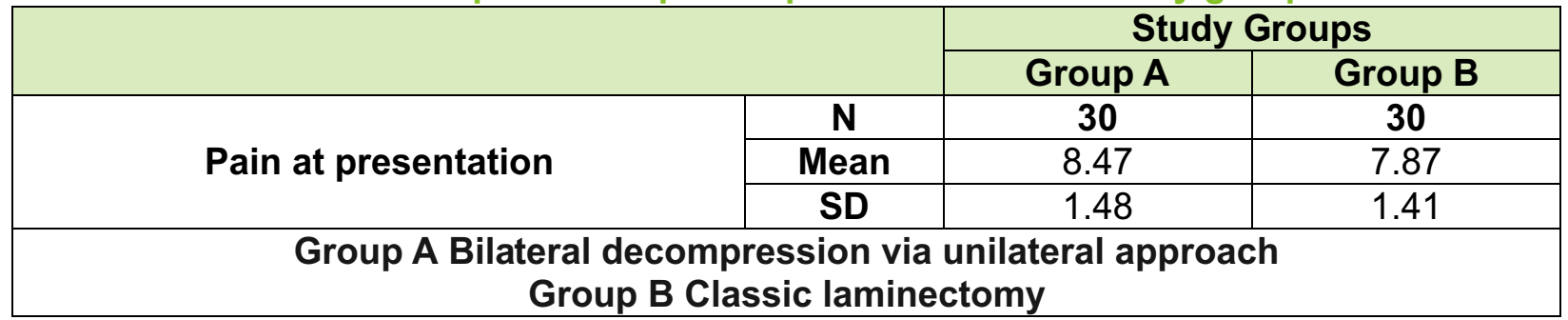

Table 2. Comparison of pain at $1^{\text {st }}$ month with study groups

\begin{tabular}{|c|c|c|c|}
\hline \multicolumn{2}{|c|}{} & \multicolumn{2}{c|}{ Study Groups } \\
\cline { 3 - 4 } & & Group A & Group B \\
\hline \multirow{3}{*}{ Pain at $\mathbf{1}^{\mathbf{s t}}$ month } & $\mathbf{n}$ & $\mathbf{3 0}$ & $\mathbf{3 0}$ \\
\cline { 2 - 4 } & Mean & 1.63 & 3.50 \\
\cline { 2 - 4 } & SD & 1.129 & 1.106 \\
\hline
\end{tabular}


Other operative options that are less invasive, such as the bilateral laminotomy and, in particular, the unilateral laminotomy for bilateral decompression, have been introduced during the past years. ${ }^{14}$ The success rate of unilateral approach in cases of bilateral decompression mentioned by different studies is $68 \%{ }^{13}$, and $85 \%,{ }^{15,16} 87 \%,{ }^{13} 88 \%,{ }^{13} 94 \%,{ }^{15,16}$

In our study the the overall mean value of pain at presentation was $8.17 \pm 1.463$. In this study the mean value of pain at $1^{\text {st }}$ month in Bilateral decompression via unilateral approach group was $1.63 \pm 1.129$ and its mean value in Classic laminectomy group was $3.50 \pm 1.106$. Statistcally Bilateral decompression via unilateral approach group showed significantly lower pain as compared to Classic laminectomy group i.e pvalue $=0.000$. Some of the studies are discussed below showing the results in favour of our study and support the Bilateral decompression via unilateral approach.

A study by Yaman $\mathrm{O}$ et al. ${ }^{1}$ demonstrated that in both groups, postoperative low back and leg pain VAS scores declined compared to the preoperative condition. Low back pain VAS scores were lower at postoperative 1, 6, and 12 months. The bleeding was higher in the classic laminectomy group, whereas the surgery time was higher in the bilateral decompression via unilateral approach group. Bilateral decompression through unilateral approach is an effective method without instability effect, which provides sufficient decompression in the degenerative stenosis and increases patient comfort in the postoperative period. In the two years follow-up results of Liu et al. showed that the atrophy rate of multifidus cross sectional areas and postoperative VAS of low back pain were lower in the group that underwent bilateral decompression via unilateral approach than the group underwent conventional laminectomy ${ }^{17}$.

Krut'ko $^{18}$ investigated less complication in the group that underwent bilateral decompression via unilateral approach for LSS than the group that underwent standard technique. One local study by ALAM et $\mathrm{al}^{12}$ showed that the unilateral approach for bilateral decompression is the better option for the patients presenting with LSS. Efficacy of unilateral approach for bilateral decompression in LSS was found in 136 $(79.53 \%)$. The report by Costa et al. on clinical outcomes of unilateral laminotomy for bilateral decompression observed significant improvement in patients with LSS. ${ }^{13}$

\section{CONCLUSION}

It has been proved in our study the bilateral decompression via unilateral approach showed significantly better post-operative back pain as compared to classic laminectomy in patients with LSS.

\section{REFERENCES}

1. Yaman O,Ozdemir N,Dagli A, Acar E,Dalbayrak S, Temiz C. A comparison of bilateral decompression via unilateral approach and classic laminectomy in patients with lumbar spinal stenosis: a retrospective clinical study. Turk Neurosurg. 2015;25(2):239-45.

2. Lee $\mathrm{JH}$,Sung $\mathrm{E}$. The effects of aquatic walking and jogging program on physical function and fall efficacy in patients with degenerative lumbar spinal stenosis. J exerc Rehabil. 2015;11(5):272-80

3. Huang W, Chang Z, Zhang J,Song $R, Y u \quad X$. Interspinous process stabilization with Rocker via unilateral approach versus X-Stop via bilateral approach for lumbar spinal stenosis: a comparative study. BMC Musculoskelet Disord. 2015;16(1):32836.

4. Müjde S,Erel N,Ozan F.Transverse decompression technique in the surgical treatment of degenerative lumbar canal stenosis. Acta Orthop Traumatol Turc. 2015;49(6):614-9.

5. Lee SY,Kim TH,Oh JK,Lee SJ,Park MS. Lumbar stenosis: a recent update by review of literature. Asian Spine J. 2015;9(5):818-28.

6. Parker SL,Anderson LH,Nelson T, Patel VV. Costeffectiveness of three treatment strategies for lumbar spinal stenosis: Conservative care, laminectomy, and the Superion interspinous spacer. Int J Spine Surg. 2015;(9): 28-35; doi: 10.14444/2028.

7. Park Y,WY Lee,Ahn JK, Nam HS, Lee KH. Percutaneous adhesiolysis versus transforaminal epidural steroid injection for the treatment of chronic radicular pain caused by lumbar foraminal spinal stenosis: a retrospective comparative study. Anns Rehabil Med.2015;39(6):941-9.

8. Kwon YJ.Central decompressive laminoplasty for treatment of lumbar spinal stenosis: technique and early surgical results. J Korean Neurosurg Soc.2014;56(3):206-10.

9. Nerland US, Jakola AS,Solheim O,Weber C, Rao V,Lønne Get al. Comparative effectiveness of microdecompression and laminectomy for central lumbar spinal stenosis: study protocol for an observational study. BMJ open. 2014;4(3):e004651.

10. Lee S,Srikantha U. Spinous Process splitting Laminectomy: Clinical outcome and Radiological analysis of extent of decompression. Int J Spine Surg.2015;9 20; doi:10.14444/2020.

11. Maruo K,Tachibana T,Inoue S,Arizumi F, Yoshiya S. Prognostic factors of surgical outcome after spinous process-splitting laminectomy for lumbar spinal stenosis. Asian Spine J. 2015;9(5):705-12. 
12. Alam I,Ullah W,Khan MI, Ali M.Effectiveness of Unilateral Approach for Bilateral Decompression in Lumber Spinal Stenosis. Pak $J$ of Neurol Surg.2015;19(4):268-75.

13. Costa F,Sassi M,Cardia A,Ortolina A,De Santis A,Luccarell G, et al. Degenerative lumbar spinal stenosis: analysis of results in a series of 374 patients treated with unilateral laminotomy for bilateral microdecompression. J of Neurosurg:Spine. 2007;7(6):579-86.

14. Hwang SW,Rhim SC,Roh SW,Jeon SR, Hyun SJ.Outcomes of unilateral approach for bilateral decompression of lumbar spinal stenosis: comparison between younger and geriatric patients.Kor J Spine. 2008;5(2):51-57.

15. AYDIN Y.Efficacy of unilateral laminectomy for bilateral decompression in lumbar spinal stenosis. Turk Neurosurg.2007;17(2):100-8.

16. Oertel MF, Ryang YM,Korinth MC, Gilsbach JM, Rohde $\mathrm{V}$. Long-term results of microsurgical treatment of lumbar spinal stenosis by unilateral laminotomy for bilateral decompression. Neurosurgery. 2006;59(6):1264-70.

17. Liu X,Yuan S, Tian Y.Modified unilateral laminotomy for bilateral decompression for lumbar spinal stenosis.Spine. 2013;38(12):pE732-E7.

18. Krut'ko AV. Results of decompressive-stabilizing procedures via unilateral approach in lumbar spinal stenosis. Zhurnal voprosy neirokhirurgii imeni NN Burdenko. 2012;76(2):33-40.
DATA SHARING STATEMENT: The data that support the findings of this study are available on request from the corresponding author. The data are not publicly available due to privacy or ethical restrictions.

CONFLICT OF INTEREST: Authors declare no conflict of interest.

GRANTED SUPPORT AND FINANCIAL DISCLOSURE: Nil

\section{AUTHOR'S CONTRIBUTION}

Following authors have made substantial contributions to the manuscript as under

Khan OA: $\quad$ Concept and design of study, Collection of data, statistical analysis

Khan MP, Azam M:Writing of manuscript, critical review of manuscript

Abideen Z: Analysis and interpretation of data, Uddin S: $\quad$ Data collection, bibliography

Authors agree to be accountable for all aspects of the work in ensuring that questions related to the accuracy or integrity of any part of the work are appropriately investigated and resolved. 